\title{
Theoretical Analysis on Aircraft Gas Turbine Engine's Control Unit
}

\author{
Surendar Ganesan ${ }^{1}$ and Monisha Priyadharshini.G ${ }^{2}$ \\ ${ }^{1,}$ Department of Aeronautical Engineering, Veltech Dr.RR \& Dr.SR Technical University, \\ Chennai, Tamil Nadu, India, \\ ${ }^{2,}$ Department of Electrical and Electronics Engineering, Veltech Multi Tech Dr. RR Dr.SR Engineering College, \\ Chennai, Tamil Nadu, India,
}

Abstract: Engine is the heart of aircraft, which makes other systems dependent on it for their proper function. This arise the situation to use an engine with high efficiency and reliability. In spite of all other types of engine, Gas turbine engine is the best suited one for modern transportation. To make the engine effective, its control system plays a vital role. In this paper all about the engine control system are discussed such as its usage, types, architecture, constraints and its future needs.

Index Terms: Electronic Engine Control, FADEC, Distributed Architecture.

\section{Introduction}

Day-by-day the usage of air transportation is increasing in world wide. It makes the people to question about the safety and comfort. Air transportation is in need to fulfill their expectations in low cost. The increase in usage of air transportation, results in the demand of oil. This leads to the condition of increase in air fare. People are not ready to pay more cost, but they need all the comforts. The solution for this problem can be find out by highly efficient engine usage. One of the remarkable achievements in mechanic field is the invention of gas turbine engine, [1]. The improvements achieved by the gas turbine over the past 70 years were by aerothermodynamics and material development. The enhancement of engine efficiency not only depends on these two things, but also the proper control systems. This paved the way for more innovations in control system like earlier hydro mechanical system changed to present day Full Authority Digital Engine Control (FADEC).

\section{Engine Control System}

Depending on the type of engine and the performance expected by it, fuel and engine controls range in complexity from simple valves to automatic computing devices containing hundreds of intricate and highly machined parts. The real fact is, in reference to fuel flow, the pilot of a gas turbine powered airplane does not directly control the engine. The pilot's relation to the power plant corresponds to that of the bridge officer on a ship who obtains engine response by relaying orders to an engineer below deck, who, in turn, actually moves the throttle of the engine. However, before moving the throttle, the engineer monitors certain operating factors that would not be apparent to the captain, such as pressures, temperatures and rpm. The engineer then refers to a chart and computes a fuel flow or throttle movement rate that will not allow the engine to exceed its operating limits.

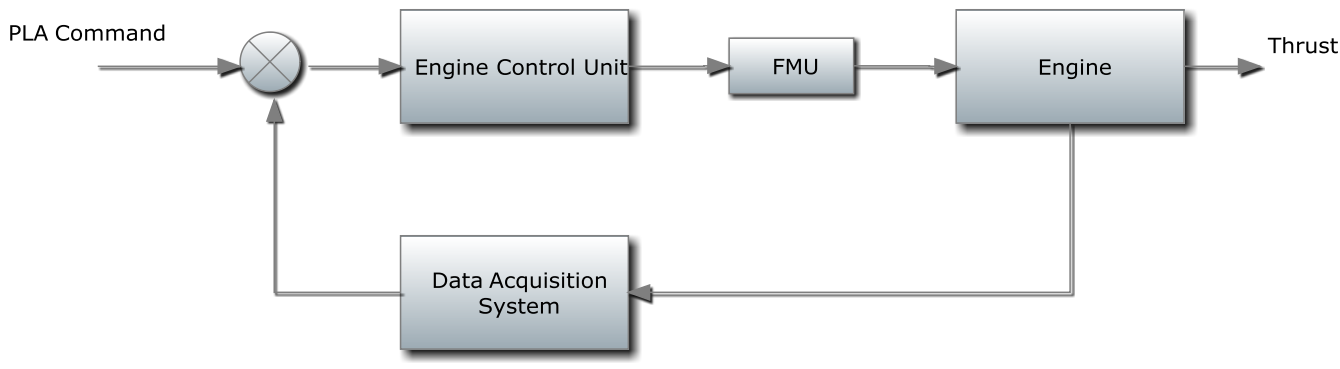

Figure - 1.1, Typical Engine Control System

\section{A. Types of Controls}

Modern fuel and engine controls can be divided into three basic groups:

- Hydro mechanical

(Pneumatic or Hydraulic)

- Electrical

(Hard wire technique) 
- Hybrid and

- Electronic

(Programmable Logic Control or Microcontrollers)

The hydro mechanical type controls consist of cams, servos, speed governors, metering valves, temperature sensing bellows etc. Electrical type controls consist of electrical amplifiers, relays, switches, solenoids, timers, tachometers, converters, thermocouples etc. Electronics controls incorporate many of the electrical functions such as amplifiers, relays, switches and timers with in the central processing unit.

The first two may sense some or all of the following engine variables:

$>$ Pilot's demands

$>$ Compressor inlet temperature

$>$ Compressor discharge pressure

$>$ Burner pressure

$>$ Rpm

$>$ Turbine temperature

\section{B. Historical Developments}

Till 1970's, control systems had no ability to store \& retrieve data and are operated only in real time. In hydro mechanical controls calibration is required frequently. They were also subjected to contamination and deterioration due to wear. Fuel flow control and compressor bleed air flow control are multiple outputs which required independent control loops. To coordinate the output of multiple loops, cascade control was used which was a difficult task. Also accuracy and response time were not achieved as expected. Manual tasks were much used [2]. For example, station valves, prelube pumps and cooling water pumps were manually placed into the running position prior to starting the gas turbine. There were limited numbers of protected devices only. To limit high turbine temperature or to shutdown the gas turbine, the margin between temperature control set points and safe operating turbine temperature was large.

In early 1970s, controls for gas turbine application were electrical controls. It was consisted of station control, a process control, and a turbine control. In this type, control functions such as start, stop, load, unload, speed and temperature were generated, biased and computed electrically. To drive servo valves employing high pressure hydraulics, output amplifiers were used. Servo valves are used to operate hydraulic actuators. The invention of programmable logic controllers and microprocessors in the late 1970's been helpful to eliminate independent control loops and facilitated multifunction control.

Table - 1.1, Historical development of Engine Control Unit

\begin{tabular}{|c|c|c|c|c|c|c|}
\hline S.No & ECU & Operating Engine & Engine Type & Manufacturer & First Run & Users \\
\hline 1 & HS JFC68 FCU & $\begin{array}{c}\text { Pratt \& Whitney } \\
\text { JT9D }\end{array}$ & Turbofan & Pratt \& Whitney & 1966 & $\begin{array}{c}\text { Boeing 747, } \\
\text { Boeing 767, } \\
\text { Airbus A310, } \\
\text { McDonnell Douglas DC-10, }\end{array}$ \\
\hline 2 & Bendix System & Allison Model 250 & Turboshaft & $\begin{array}{c}\text { Allison Engine } \\
\text { Company }\end{array}$ & $1960 \mathrm{~s}$ & $\begin{array}{c}\text { Bell 206, } \\
\text { MD Helicopters MD 500, } \\
\text { MBB Bo 105, } \\
\text { Sikorsky S-76, }\end{array}$ \\
\hline 3 & HS EEC103 & $\begin{array}{l}\text { Pratt \& Whitney } \\
\text { JT9D-7R4 }\end{array}$ & Turbofan & Pratt \& Whitney & $1960 \mathrm{~s}$ & Boeing 767, Airbus A310, \\
\hline 4 & Woodward FCU & General Electric CF6 & Turbofan & GE Aviation & 1971 & $\begin{array}{c}\text { Airbus A300, } \\
\text { Airbus A330, } \\
\text { Boeing 747, } \\
\text { Boeing 767, } \\
\text { McDonnell Douglas DC-10, } \\
\text { McDonnell Douglas MD-11, }\end{array}$ \\
\hline 5 & Garrett DFC & Garrett TFE731 & $\begin{array}{l}\text { Geared } \\
\text { turbofan }\end{array}$ & $\begin{array}{l}\text { Honeywell } \\
\text { Aerospace }\end{array}$ & $1970 s$ & $\begin{array}{c}\text { CASA C-101, } \\
\text { Cessna Citation III, } \\
\text { Learjet 31, }\end{array}$ \\
\hline 6 & HS EEC104 & $\begin{array}{l}\text { Pratt \& Whitney } \\
\text { PW2037 }\end{array}$ & Turbofan & Pratt \& Whitney & 1984 & $\begin{array}{c}\text { Boeing 757, } \\
\text { C-17 Globemaster III, } \\
\text { Ilyushin II-96M, }\end{array}$ \\
\hline
\end{tabular}




\section{Electronic Engine Control (FADEC)}

The electronic controls, especially the Full Authority Digital Electronic Control (FADEC), which may be a part of sophisticated engine control (EEC) system, will sense many operating parameters. Electronic control systems may also be fiber optics instead of wire to provide immunity from electromagnetic (EM) effects. Fiber optic systems are safer, have fewer components and require less maintenance. Full authority digital engine is a system consisting of digital computer, called an electronic engine controller and its related accessories that control all aspects of aircraft engine performance. The FADEC, shown in fig-1.2, is the primary interface between the engine and the aircraft. It is located in fan case of an engine.

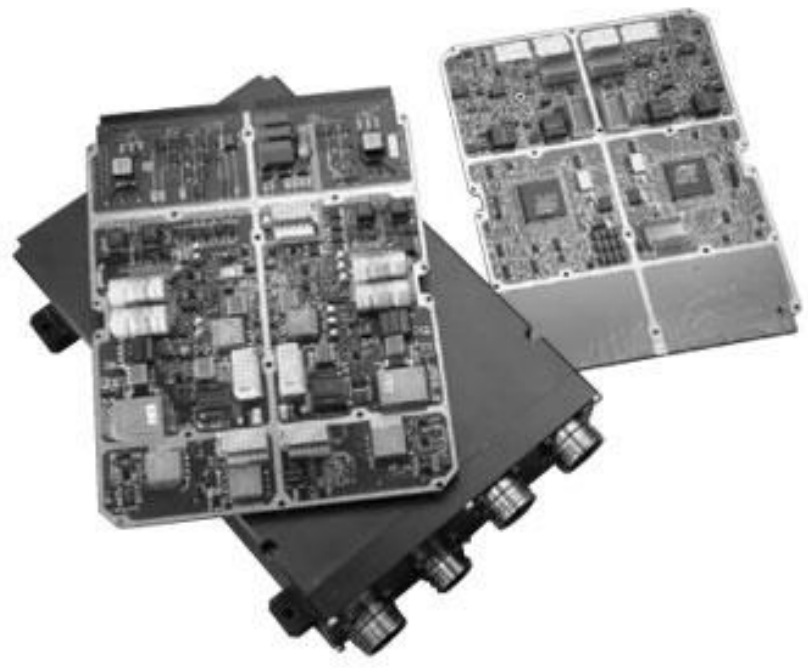

Figure - 1.2, FADEC

\section{Engine Control Architecture}

Presently, engine control system architecture is based on a centralized design in which discrete sensors and effectors are directly wired to an engine-mounted electronics package. This avionics unit, often known as the FADEC, contains all the necessary circuitry to properly interface with engine control devices as well as cockpit command and data communications. The design of a centralized engine control system is primarily based on the single overriding concern of minimal control system weight because of its effect on overall vehicle performance, [3]. Much of the design is based on legacy, the result of incremental improvement over many years. This constraint severely limits the design choices for avionics engineers.

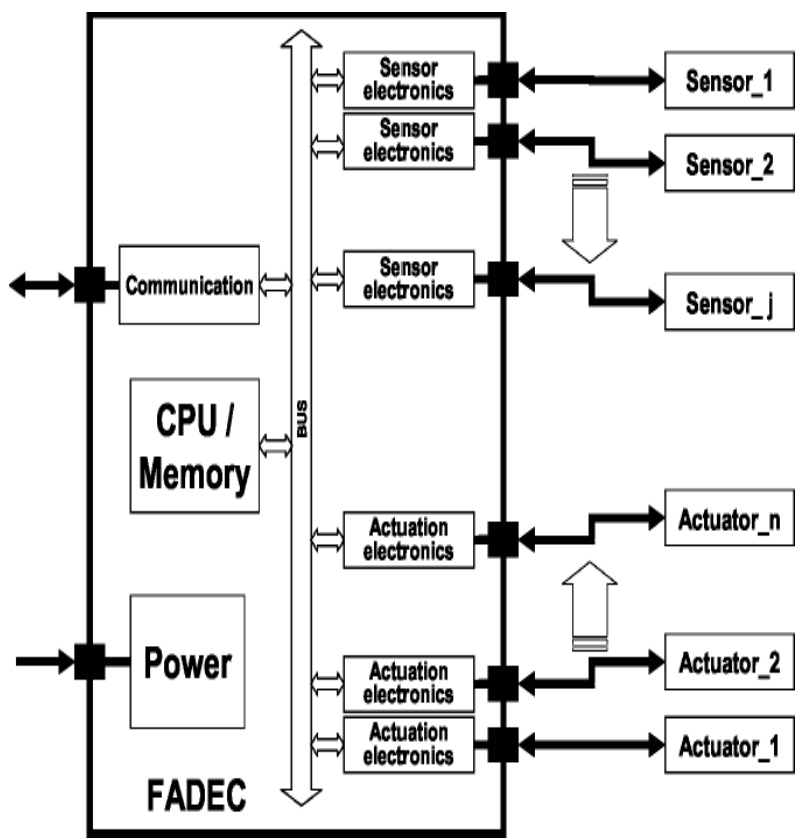

Figure - 1.3, Centralized Engine Control Architecture 


\section{A. centralized architecture}

In a centralized architecture weight is primarily driven by the quantity and location of control system elements. Due to these weight restrictions and the limited availability of engine access points, there is a very significant pressure to minimize the number of sensors and effectors. With a limited number of control elements each have to be designed with the utmost reliability and well-understood failure modes. In order to drive element MTBF (Mean Time Between Failure) to an acceptable level, dual-redundancy is often used. The end result is a very high weight penalty in connecting the control element to the FADEC due to the number of conductors required and the construction of the wire harness. The weight penalty is minimized by locating the FADEC in near proximity on the engine structure.

The engine structure is a quite severe environment for an avionics package. Vibration and temperature extremes, force the electronics to be custom designed for a specific engine. Circuit components are specifically designed for maximum density to achieve small physical size thereby increasing stiffness and raising the natural frequency of resonant mechanical vibration modes. This adversely affects heat dissipation in the assembly. The large number of conductors and the physical size of the connector shells mounted on the FADEC enclosure often drive the package dimensions. The entire package must be mounted on low frequency isolators to reduce the shock loads experienced over a mission profile. Temperature extremes at the engine structure require cooling to reduce the operating temperature of semiconductor junctions to an acceptable level. This is maintained by conduction cooling the entire assembly with a cold plate using the aircraft fuel supply as the heat removal media.

Under centralized engine control system architecture, the need to reduce overall weight drives a chain of design constraints which result in an optimized engine control system, but one which is costly to both procure and maintain. Furthermore, because it is so highly optimized, it is inflexible to use in multiple platforms or even to accommodate upgrades in an existing application. Changing the engine control architecture to a distributed system can radically alter the interrelated chain of constraints which ultimately drive overall cost of ownership.

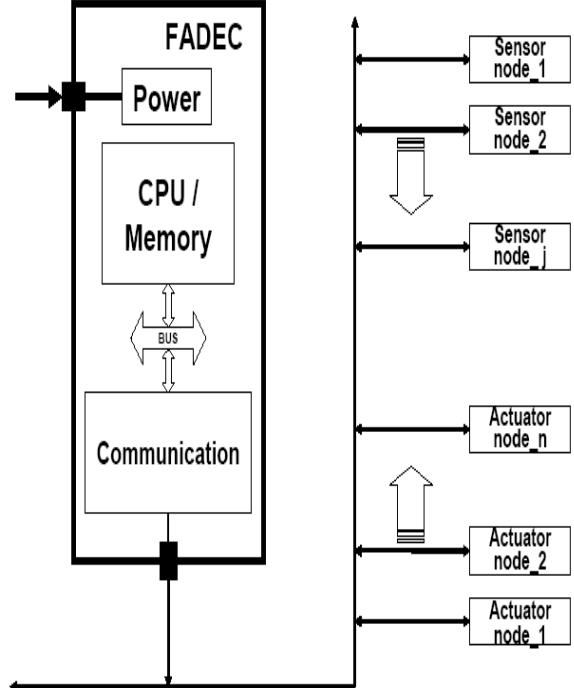

Figure - 1.4, Distributed Engine Control Architecture

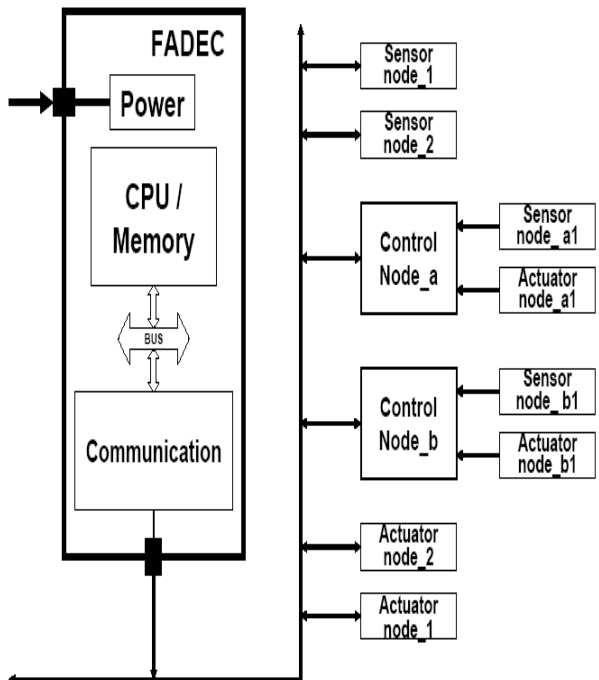

Figure - 1.5, Extended Distributed Engine Control Architecture

\section{B. Distributed Engine Control Architecture}

In a distributed engine control system architecture, shown in Fig-1.4, any number of control elements are tied together through a common, standardized, communication interface. Sensors and effectors are replaced by control nodes in order to provide sensor data, operate actuators, or perform combinations of both. The massive wiring harness which previously tied together the control element to interface circuitry in the engine-mounted avionics package is replaced by a simple but robust communication structure. Weight reduction is the primary motivation but the standardized interface is also an enabling feature which is necessary to effectively implement future adaptive control applications.

Control nodes in distributed control system architecture are by definition "intelligent." Sensor nodes produce information about the physical state of the engine using a predefined data structure. This could take the form of a stream of temporal data in engineering units or a pre-processed state of an engine function, e.g. "impending stall." Similarly, actuator nodes receive commands and/or data from one or more sources to intelligently operate an engine actuator at its most efficient configuration. In some instances, especially in new adaptive control applications like stall avoidance, high bandwidth, high response control may require nested control nodes which perform both sensing and actuation beneath the overall control communication structure. This is shown in Fig-1.5 
The overall system control is still coordinated by the FADEC. This is now physically much smaller. Its function becomes one of the processing and communications. Since the communication network is standardized there is no longer a need for unique interface and signal conditioning circuitry for each control element. The number of conductors in each wiring harness and the connector shells do not dictate the avionics package configuration. The location of the FADEC is no longer critical allowing the most complex electronics hardware to be relocated in a more benign environment.

In a distributed engine control architecture weight optimization no longer drives the design and packaging of the FADEC [8]. This leads to broad cross platform standardization and significant cost reductions in both acquisition and maintenance. The issue of system upgrade becomes one largely focused on software requalification instead of complete system re-qualification.

\section{Summary}

In an engine control system, though its architecture \& design procedure are applicable to any commercial aircraft engine, it failed to provide an emergency module. Thus it doesn't have redundancy [5]. From the analysis and papers of some authors on distributed engine control [6], [7], [8], [9], [10], it's clear that there are many propulsion engine system constraints. Apart from those constraints, there are some benefits in distributed control architecture. There is a difference between two channel configuration and mixed channel system (with Hydro mechanical backup). Both of these redundant systems are not capable for the future aero propulsion. Hence there is a need for most advanced redundant system. Along with these, there is a necessity to know about sensor validation, present control sensors, and future strategy for sensors and common standards for sensors.

\section{Future Enhancement}

In the upcoming years there is a need for techniques like Image Processing can be done to acquire data; by using Adaptive Model - Based Control Technique, the rise in errors due to sensors can be avoided; by introducing Neural Controllers, engine can make its own decision in advert situations, without the intervention of human activities (Smart Engines).

\section{Conclusion}

In this paper, authors reviewed Engine Control System, Types of Engine Control Unit, Historical Developments of engine control units and present Digital Engine Controller with its architecture. Also authors discussed about future requirements of engine control system. Since the existing system is not proving its redundancy, the major improvement should be done in architecture, along with the introduction of advanced emergency module.

\section{References}

[1] Irwin E. Treager, "Aircraft Gas Turbine Engine Technology”, Third Edition, Tata McGraw-Hill, ISBN-13: 978-0-07-463111-9

[2] Tony Giampaolo, "Gas Turbine Handbook: Principles and Practices”, Fourth Edition, The Fair Mont Press, ISBN-13: 978-1-43980191-8

[3] A. Chipperfield and P. Fleming, 1996, "Multiobjective Gas Turbine Engine Controller Design Using Genetic Algorithms", IEEE Transactions on Industrial Electronics, Vol. 43

[4] A. J. Chipperfield and P. J. Fleming, 1998, "Evolutionary Design of Gas Turbine Aero-Engine Controllers”. In Proceedings of the IEEE International Conference on Systems, Man, and Cybernetics

[5] Hjelmgren.K, Svensson.S, and Hannius.O, 1998, "Reliability Analysis of a Single Engine Aircraft FADEC", Reliability and Maintainability Symposium, IEEE Conference Publication, 10.1109/RAMS.1998.653811

[6] Raj Subbu, Kai Goebel, and Dean K. Frederick, 2005, "Evolutionary Design and Optimization of Aircraft Engine Controllers", IEEE Transactions on Systems, Man, and Cybernetics, IEEE Journals \& Magazines, 10.1109/ TSMCC.2004.843250

[7] Alireza R. Behbahani, 2006, "Need for Robust Sensors for Inherently Fail-Safe Gas Turbine Engine Controls, Monitoring, and Prognostics", 52 ${ }^{\text {nd }}$ International Instrumentation Symposium, Cleveland, AFRL-PR-WP-TP-2007-217

[8] Dennis E. Culley, Randy Thomas, and Joseph Saus, 2007, “Concepts for Distributed Engine Control”, 43 ${ }^{\text {rd }}$ AIAA Joint Propulsion Conference \& Exhibit, Cincinnati, AIAA-2007-5709

[9] Rama K. Yedavalli, and Rohit K. Belapurkar, 2008, "Stability Analysis of Distributed Engine Control Systems under Communication Packet Drop", 44 ${ }^{\text {th }}$ AIAA Joint Propulsion Conference \& Exhibit, Hartford, AFRL-RZ-WP-TP-2008-2189

[10] Dennis Culley and Sanjay Garg, 2009, "More Intelligent Gas Turbine Engines", Research and Technology Organization of NATO, RTO-TR-AVT-128

[11] Dennis E. Culley, Paul J. Paluszewski and Bert J. Smith, 2009, "The Case for Distributed Engine Control in Turbo-Shaft Engine Systems", $65^{\text {th }}$ Annual Forum and Technology Display, Texas, NASA/TM-2009-215654

[12] M. Bazazzadeh, H. Badihi, and A. Shahriari, 2009, "Improved Turbine Engine Hierarchical Modeling and Simulation Based on Engine Fuel Control System", 45 ${ }^{\text {th }}$ AIAA Joint Propulsion Conference \& Exhibit, Denver, AIAA-2009-5525

[13] Walter Merrill, Jong Han Kim, Sanjay Lal, and Steve Majerus, 2010, "Distributed Engine Control Design Considerations", 46" AIAA Joint Propulsion Conference \& Exhibit, Nashville, AIAA-2010-6749

[14] Csank. J, May. R. D, Litt. J.S and Guo. T, 2010, “Control Design for a Generic Commercial Aircraft Engine”, 46 ${ }^{\text {th }}$ AIAA Joint Propulsion Conference \& Exhibit, Nashville, AIAA-2010-6629

[15] Avishai Weiss, and Ilya Kolmanovsky, 2011, “Incorporating Risk into Control Design for Emergency Operation of Turbo Fan Engines", Infotech Aerospace Conference, Missouri, AIAA-2011-1591 